\title{
Bridging Chemotherapy: Follicular Lymphoma, Mantle Cell Lymphoma, and CLL
}

\author{
Nico Gagelmann, John Gribben 이, and Nicolaus Kröger (1)
}

While lisocabtagene maraleucel (liso-cel) is the only product that is specifically approved to treat grade 3B follicular lymphoma (FL), specifically in aggressive lymphoma indications, to date, axi-cel is the first and only approved CAR-T product for indolent NHL.

ZUMA-5 is a phase 2 study of axi-cel in patients with indolent NHL (including FL and marginal zone lymphoma (MZL)) treated with two or more prior lines of systemic therapy, with prior exposure to both an alkylating agent and anti-CD20 therapy (Jacobson et al. 2021). Of the 104 patients evaluable for efficacy, the ORR was $92 \%$ and the CR was $76 \%$. For the 84 patients with FL, the ORR was $95 \%$ (CR $80 \%$ ), and for the 20 patients with MZL, the ORR was $85 \%$ (CR 60\%). No differences between prior treatments were noted, while to date, specific analyses according to bridging have not yet been presented. In the ELARA trial on tisa-cel in FL, 97 patients received treatment (median follow-up time, 10.6 months) (Schuster et al. 2021). The median number of prior therapies was 4 (range, 2-13); 78\% of patients were refractory to their last treatment ( $76 \%$ to any $\geq 2$ prior regimens) and $60 \%$ progressed within 2 years of initial anti-CD20-containing treatment. The CR rate was $66 \%$, and the ORR was $86 \%$, which was comparable among key subgroups, including bridging.

However, notably, indolent NHL is a chronic disease that can relapse after years of remission. Although the rates of continued CR and PFS at 12 months reported in ZUMA-5 are encouraging, a longer follow-up time is needed to identify patients who benefit the most from certain treatment sequences.

\footnotetext{
N. Gagelmann · N. Kröger $(\bowtie)$

Department of Stem Cell Transplantation, University Medical Center Hamburg-Eppendorf, Hamburg, Germany

e-mail: n.gagelmann@uke.de; n.kroeger@uke.de

J. Gribben

Bart's Cancer Institute, Queen Mary University of London, London, UK

e-mail: j.gribben@qmul.ac.uk 
Among relapsed or refractory mantle cell lymphoma patients receiving KTEX19 CAR-T therapy (Wang et al. 2020), a total of 25 patients (37\% of the total cohort) received bridging therapy with ibrutinib (14 patients), acalabrutinib (5), dexamethasone (12), or methylprednisolone (2). The majority of the patients who had assessments both before and after bridging therapy showed an increase in the median tumour burden after the receipt of bridging therapy. Response rates were similar regardless of exposure to bridging therapy, but ongoing responses seemed to be higher in patients without bridging therapy (67\% vs. 38\%).

With regard to chronic lymphocytic leukaemia, the TRANSCEND CLL 004 study of liso-cel included patients with standard or high-risk features treated with $\geq 3$ or $\geq 2$ prior therapies (Siddiqi et al. 2021), respectively, including Bruton kinase inhibitors. A total of 17 patients (74\%) received bridging therapy during liso-cel manufacturing, and response rates were consistent, with $82 \%$ and $45 \%$ achieving overall and complete responses, respectively. Safety and efficacy were similar between treatment groups. Another small study even suggested the feasibility of concurrent ibrutinib with CD19 CAR-T therapy (Gauthier et al. 2020), but the population overall is still limited, and studies are ongoing.

\section{Key Points}

- Limited evidence on the role of bridging therapy in FL and indolent lymphoma.

- Systemic therapy led to worse outcomes across lymphoma types, but the reasons are elusive.

- Bendamustine should be avoided whenever possible.

- The association between tumour volume before and after bridging therapy and the overall response after CAR-T cell therapy is still unclear in mantle cell lymphoma.

- Bridging therapy in CLL with BTKi seems feasible.

\section{References}

Gauthier J, Hirayama AV, Purushe J, et al. Feasibility and efficacy of CD19-targeted CAR-T cells with concurrent ibrutinib for CLL after ibrutinib failure. Blood. 2020;135:1650-60.

Jacobson CA, Chavez JC, Sehgal AR, et al. Outcomes in ZUMA-5 with axicabtagene ciloleucel in patients with relapsed/refractory indolent non-Hodgkin lymphoma who had the high-risk feature of early progression after first chemoimmunotherapy. Abstract \#S213. Presented at the EHA2021 Virtual Congress 2021 Jun 9.

Schuster SJ, Dickinson MJ, Dreyling MH, et al. Efficacy and safety of tisagenlecleucel (Tisa-cel) in adult patients (Pts) with relapsed/refractory follicular lymphoma ( $\mathrm{r} / \mathrm{r} \mathrm{FL})$ : primary analysis of the phase 2 Elara trial. J Clin Oncol. 2021;39:7508.

Siddiqi T, Soumerai JD, Dorritie KA, et al. Phase 1 TRANSCEND CLL 004 study of lisocabtagene maraleucel in patients with relapsed/refractory CLL or SLL. Blood. 2021;

Wang M, Munoz J, Goy A, et al. KTE-X19 CAR-T cell therapy in relapsed or refractory mantlecell lymphoma. N Engl J Med. 2020;382:1331-42. 
Open Access This chapter is licensed under the terms of the Creative Commons Attribution 4.0 International License (http://creativecommons.org/licenses/by/4.0/), which permits use, sharing, adaptation, distribution and reproduction in any medium or format, as long as you give appropriate credit to the original author(s) and the source, provide a link to the Creative Commons license and indicate if changes were made.

The images or other third party material in this chapter are included in the chapter's Creative Commons license, unless indicated otherwise in a credit line to the material. If material is not included in the chapter's Creative Commons license and your intended use is not permitted by statutory regulation or exceeds the permitted use, you will need to obtain permission directly from the copyright holder.

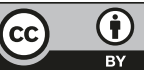

